\title{
We Already have Sufficient Technology to Eliminate Hunger
}

\section{Kenneth S Marsh*}

Woodstock Institute for Science and the Humanities, USA

*Corresponding Author: Kenneth S Marsh, Woodstock Institute for Science and the Humanities, USA.

Received: September 16, 2019; Published: September 24, 2019

\section{Introduction}

As scientists, we are significantly better at speaking among ourselves than communicating with those outside of our sphere of influence. This often leads to assumptions that can be detrimentally false. These false assumptions, in my opinion, have contributed to our collective failure to meet the 1st Millennium goal to reduce world hunger by $50 \%$ by 2015 in spite of wonderful efforts that allowed many countries to achieve local success.

I believe we can do better through a combination of political will and a desire to apply our collective knowledge to make a difference that we know is not only possible, but absolutely necessary as we acknowledge that climate change and population growth are working against that goal. We have resources sufficient to meet and exceed that $50 \%$ goal, so let us review some of those resources and choose to add new ideas to our arsenal.

\section{Resources many do not recognize}

In 1991, as now, many people were concerned about the impact of packaging waste on the environment. I had published a Scientific Status Summary on packaging waste [1] and was asked to represent the US at the International Symposium on Packaging, Solid Waste, and the Environment. The so-called developed world (Germany, Great Britain, Switzerland, etc.) were discussing the problems with packaging waste when the delegate from Vietnam stated that if we didn't want those packaging materials, please send them to Vietnam because they had a major problem with food waste due to lack of packaging materials. In 1991, food packaging in Vietnam was primarily HDPE.

I began researching food losses and found resources such as Malcolm Bourne's excellent report on post-harvest food losses from 1978 [2] and many new developments. But there was a dearth of more general approaches to reduce post-harvest damage.

I am as guilty as many I am attempting to address in this opinion. I accepted an endowed professorship in the USA on the basis that I would found a Center for Global Food Security (GFS) in 1997. The idea was to investigate food loss and waste, identify causes, and develop remedies to reduce those losses.

Food loss and waste were always significant, but international cooperative efforts were overwhelmingly focused on food production through breeding, soil conditioning and pest management. For example, The Consultative Group International Agricultural Research (CGIAR) included 15 research centers to improve food production but food loss and waste was never identified as a scientific priority until after FAO presented two reports on food losses at the $1^{\text {st }}$ Save Food Congress in $2011[3,4]$. I presented "Reducing Food Losses through International Cooperation/exchange of Postharvest Technologies" at that same congress and will expand on some of the ideas below. But the issue is that prior to 2011, little international efforts addressed food losses. I made a presentation to FAO in 2001 [5] and FAO had approximately 5000 employees, only 3 of whom were Senior Post Harvest officers.

Although international efforts did not emphasize food losses before 2011, many countries conducted research on aspects of food production and distribution. Research institutes published evaluation methods and multiple cutting edge technologies. But it seemed that more mundane problems that led to food losses were not addressed. I was admittedly naïve when I promoted the center in 1997. In 2004 I was invited to participate in a short course on 
post-harvest technology in Sri Lanka and invited to visit their Institute of Post-Harvest Technology (IPHT) after the course. I had not known of the existence of IPHT but found a sophisticated institute with over three dozen projects doing precisely what I had proposed with the Center for GFS. I soon found that post-harvest institutes around the globe were doing fabulous work on "appropriate" technologies, i.e. both simple and sophisticated means to reduce food losses. But many do not have budgets to participate in international conferences, and many do not publish their research in English or other UN languages. So their work does not appear in the scientific literature and my 30+ years in the field did not clue me in. I strongly believe that collectively the remedies developed by these institutes, if applied beyond the countries of origin's borders, are more than sufficient to recover sufficient food to feed everyone on earth (distribution to those in need is a separate challenge). It is a challenge to identify those studies that are not presented in our traditional forums, but doing so is easier, faster and cheaper than developing that research separately.

\section{Regulatory considerations}

I grew up in the USA that developed a concept in 1865 that, in my opinion, remains one of the best inventions in the world. I refer to the Morrill Act of 1865 and subsequent acts that set up agricultural research institutes in every state, and included a mandate that the results of that research be shared with farmers (extension service). This, with the abundance of land and rich soil, made the US a very efficient food producer, and offered us the time and resources (we spend less time and money -as proportion of income -feeding ourselves than other nations) to develop a premier economy. I would welcome this model be extended to a global effort to reduce hunger, perhaps through international organizations such as FAO and scientific organizations such as the International Union of Food Science \& Technology (IUFoST) and World Packaging Organization, that could morph their existing efforts into a more goal-oriented entity.

Countries have regulations that promote safe food. These regulations set standards for safe processing, define acceptable food additives, and identify standards. "Safety" remains a difficult concept in that it is based on a lack of hazards. So regulations may define if or how much of a "hazardous" ingredient (e.g. pesticide, hormones, antibiotics, insect parts, etc.) are allowed. It is easy to set a zero tolerance, but "zero" with today's analytical capabilities, could ban, for example, all spices with detectable but not hazardous levels of hazardous or undesirable substances (e.g. insect parts). So a judgment is required. I propose that hunger (or starvation) be included as a food hazard, thereby requiring a risk/benefit analysis for setting levels of components that allow discourse, and thereby avoid inappropriate destruction of viable food.

Carrying the idea of regulations further, the Global Harmonization Initiative was established to promote food regulations based on safety and scientific evidence, and eliminate those not based on safety (e.g. size, shape, color, etc.)

I wish to close with an idea that has been presented in numerous international forums and published as Village Level Food Processing [6]. It was developed by the SE Regional office for FAO, initially implemented in SE Asia, and now expanded into Africa. The concept is to offer training programs in basic food sanitation and processing, supply basic equipment to promote village level formation of cottage industries to convert short shelf life foods into value-added products. For example, ripe banana, with a useable life of days, can be sliced, fried and packaged as banana chips with a shelf life of weeks. These chips can be sold to promote economic development. Otherwise wasted food is thereby converted into value-added products.

Global food production is sufficient to feed every person on earth, but FAO reports that $1 / 3$ of that production is lost or wasted. We have sufficient postharvest technologies to reduce those losses by more than the $16.5 \%$ I calculate is required to eliminate hunger. Let's do it!

\section{Bibliography}

1. K S Marsh. "Effective Management of Food Packaging: From Production to Disposal". A Scientific Status Summary, Food Technology 45 (1991): 225.

2. National Research Council. Postharvest Food Losses in Developing Countries. Washington, DC: The National Academies Press (1978).

3. Global Food Losses and Food Waste. Food and Agriculture Organization of the United Nations, Rome, Italy (2011).

4. Appropriate Food Packaging Solutions for Developing Countries. Food and Agriculture Organization of the United Nations, Rome, Italy (2011). 
5. KS. Marsh. "Expanding Global Food Supplies without increasing Production?". presented at FAO during the World Food Summit: five years later international summit Rome, Italy (2002).

6. Alastair Hicks. "Village Level Processing: Empowerment Through Enterprise Skills Development in Lao PDR, Myanmar and Viet Nam". Chapter 5 from Using Food Science and Technology to Improve Nutrition and Promote National Development, Robertson, G.L. \& Lupien, J.R. (Eds), (C) International Union of Food Science and Technology (2008).

\section{Volume 3 Issue 10 October 2019}

(C) All rights are reserved by Vijaya Khader. 